\section{Insights into the clinical management of carbapenem- resistant Gram-negative infections: An Italian retrospective clinical chart review}

Guido Granata, ${ }^{1}$ Davide Manissero, ${ }^{2,3}$ Maria Vittoria Oppia, ${ }^{4}$ Keiko Tone, ${ }^{2}$ Bin Cai, ${ }^{5}$ Christopher Longshaw, ${ }^{2}$ Carolina Venditti, ${ }^{6}$ Nicola Petrosillo ${ }^{7}$

${ }^{1}$ Severe and Immunocompromised-associated Infection Unit, National Institute for Infectious Diseases

Lazzaro Spallanzani, Scientific Institute for Treatment and Inpatient Care, Rome, Italy; ${ }^{2}$ Shionogi B.V., London, UK; ${ }^{3}$ University College of London, Institute for Global Health, London, UK; ${ }^{4}$ Shionogi Srl, Rome, Italy; ${ }^{5}$ Shionogi Inc., Florham Park, NJ, USA; ${ }^{6}$ Microbiology Unit, National Institute for Infectious Diseases Lazzaro Spallanzani, IRCCS, Rome, Italy; ${ }^{7}$ Clinical and Research Department, National Institute for Infectious Diseases Lazzaro Spallanzani, Scientific Institute for Treatment and Inpatient Care, Rome, Italy

\footnotetext{
Abstract

There is a lack of consensus regarding management of infections with carbapenem-resistant Gram-negative (CR-GN) pathogens. This study comprised a medical chart review to assess patient management in a high CR prevalence setting. Data was collated retrospectively from medical records of patients hospitalized between November 1 $1^{\text {st }}, 2015$ and October 31 $31^{\text {st }}, 2016$. Of 29 patients, $66 \%$ had respiratory tract infections. Median duration of hospitalization was 28 days and $~ 50 \%$ of patients were admitted to the intensive care unit, with $77 \%$ remaining for $>2$ weeks. Median time to obtain respiratory culture results was 5 days. Isolation of patients with diagnosed CR-GN infection took $\geq 5$ days in $>50 \%$ of patients. A majority $(76 \%)$ of patients received $\geq 1$ antibiotic before providing a specimen for culture; a total of 17 antibiotic treatments were used. Overall, $72 \%$ of patients, and $68 \%$ of those with respiratory infections, were discharged alive; $38 \%$ were discharged without further antibiotics. The difficulties in achieving effective management in patients with CR-GN infections are largely due to complex co-morbidities, a
}

history of prior antibiotic treatment, and multiple referrals across health care facilities.

\section{Introduction}

Antibiotic resistance is a critical public health concern, influencing survival of a range of bacterial pathogens. ${ }^{1,2}$ Carbapenemresistant Gram-negative (CR-GN) pathogens including Acinetobacter baumannii, Pseudomonas aeruginosa, Klebsiella pneumoniae and Escherichia coli are considered by the World Health Organization to be critical priority pathogens for developing new antibiotics. $^{3}$ The European Antimicrobial Resistance Surveillance Network (EARSNet) has documented a dramatic increase in carbapenem resistance over the past decade, particularly in Southern and Eastern Europe. ${ }^{4}$ In Italy, $K$. pneumoniae carbapenem resistance rates have risen sharply $(<2.0 \%$ in 2009 to $33.5 \%$ in 2015$),{ }^{4}$ with a similar trend observed in non-fermentative bacteria (23.0\% $P$. aeruginosa isolates from Italy were carbapenem resistant in $2015 ; 20.0 \%$ of clinical isolates resistant to $\geq 3$ antibiotic classes). ${ }^{4}$ For $A$. baumannii, combined resistance to carbapenems, fluoroquinolones and aminoglycosides has reached endemic levels at $\sim 75.0 \%{ }^{4}$ The prevalence of CR-GN pathogens in Italy has driven an increase in prescriptions of colistin accompanied by an alarming rise in colistin-resistance, including increased transmission of the $\mathrm{mcr}-1$ gene., ${ }^{4,5}$ Widespread resistance to broad-spectrum antibiotics has compromised their utility as empiric regimens, and is associated with delays in achieving adequate treatment, leading to increased morbidity and mortality. ${ }^{6}$ An additional concern is that CR-GN pathogens are increasingly isolated from lower respiratory tract infections and cases of hospitalacquired pneumonia, where they have been associated with a higher risk of mortality compared with other infection sites. ${ }^{6-8}$ There is a lack of consensus on the management of infections with CR-GN pathogens. In order to assess patient management in a setting of high CR prevalence, we performed a pilot retrospective medical chart review of patients infected with CR-GN pathogens at an Italian infectious diseases referral hospital.

\section{Materials and Methods}

\section{Ethics}

This was a retrospective study, which involved anonymous data collection from existing medical records, without any direct contact with patients; therefore, informed
Correspondence: Guido Granata, National Institute for Infectious Diseases Lazzaro Spallanzani, IRCCS, Rome, Italy.

Tel: +390655170432 - Fax: +390655170315. E-mail: guido.granata@inmi.it

Key words: Antibiotic resistance, carbapenem resistance, multi-drug resistance, Gram-negative bacteria, clinical management.

Acknowledgments: The authors would like to acknowledge Sarah Jackson, $\mathrm{PhD}$, of iMed Comms, Macclesfield, UK, an Ashfield Company, part of UDG Healthcare plc, for editorial support in accordance with Good Publications Practice (GPP3) guidelines (http://www.ismpp.org/gpp3)

Contributions: GG, CV and NP planned the study, and collected and analyzed the data. All authors commented, reviewed and approved the final version of the manuscript.

Conflict of interest: GG and CV declare no conflict of interest. NP reports grants from Shionogi Ltd, during the conduct of the study. $\mathrm{CL}, \mathrm{MVO}, \mathrm{KT}$ and $\mathrm{BC}$ are employees of Shionogi. DM was an employee of Shionogi at the time of the analysis.

Funding: This work was supported by Shionogi Inc. and Shionogi Ltd. Medical writing support was funded by Shionogi B.V.

Compliance with ethical standards: All procedures performed in studies involving human participants were in accordance with the ethical standards of the institutional research committee (the Ethical Committee of the National Institute for Infectious Diseases Lazzaro Spallanzani, Scientific Institute for Treatment and Inpatient Care (IRCCS); Approval number 29/2017, April 10, 2017) and with the 1964 Helsinki declaration and its later amendments or comparable ethical standards.

Ethics approval and consent to participate: This work was approved by the Ethical Committee of the National Institute for Infectious Diseases Lazzaro Spallanzani, Scientific Institute for Treatment and Inpatient Care (IRCCS); Approval number 29/2017, April 10, 2017.

Informed consent: Informed consent is not required.

Received for publication: 21 February 2020 Accepted for publication: 12 May 2020.

This work is licensed under a Creative Commons Attribution-NonCommercial 4.0 International License (CC BY-NC 4.0).

C Copyright: the Author(s), 2020

Licensee PAGEPress, Italy

Infectious Disease Reports 2020; 12:8510

doi:10.4081/idr.2020.8510 
consent was not required. Local ethical approval was obtained prior to initiation of the chart review.

\section{Study design and patients}

Patients aged $\geq 18$ years with laboratory-confirmed or clinically-documented CR-
GN infections (A. baumannii, P.aeruginosa, $K$. pneumoniae or $E$. coli) who were hospitalized during the study period of November $1^{\text {st }}, 2015$ to October $31^{\text {st }}, 2016$ in a 200-bed intensive care unit of an Italian hospital were selected. Patients with incomplete medical records were excluded. A pur- posely developed data collection form was used to collate data from existing medical records, including details of demographics,

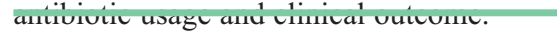

\section{Results}

Twenty-nine patients were retrospectively identified during the study period,

Table 1. Clinical characteristics by pathogen of 29 patients with documented carbapenem-resistant Gram-negative infections from an Italian infectious diseases referral centre (November $1^{\text {st }}$, 2015 - October $31^{\text {st }}, 2016$ ).

\begin{tabular}{|c|c|c|c|c|}
\hline Variable & obacter baumannii & Pseudomonas aeruginosa & Klebsiella pneumoniae & Total \\
\hline Number of patients, & $12(41.4)$ & $13(44.8)$ & $4(13.8)$ & $29(100)$ \\
\hline $\begin{array}{l}\text { Patient demographics } \\
\text { Age, years, mean (SD) } \\
\text { Age } \geq 65 \text { years } \\
\text { Men }\end{array}$ & $\begin{array}{c}52.4(16.7) \\
3(25.0) \\
11(91.7) \\
\end{array}$ & $\begin{array}{l}49(18.9) \\
4(30.8) \\
11(84.6)\end{array}$ & $\begin{array}{l}47.5(27.6) \\
2(50.0) \\
4(100)\end{array}$ & $\begin{array}{l}50.2(18.6) \\
9(31.0) \\
26(89.7)\end{array}$ \\
\hline Private residence & $8(66.7)$ & $7(53.8)$ & $2(50)$ & $17(58.6)$ \\
\hline $\begin{array}{l}\text { Admission source } \\
\text { Direct admission } \\
\text { Emergency room } \\
\text { Transfer from MCF }\end{array}$ & $\begin{array}{l}3(25.0) \\
6(50.0) \\
3(25.0)\end{array}$ & $\begin{array}{l}1(7.7) \\
5(38.5) \\
7(53.8)\end{array}$ & $\begin{array}{c}0(0) \\
1(25.0) \\
3(75.0)\end{array}$ & $\begin{array}{l}4(13.8) \\
12(41.4) \\
13(44.8)\end{array}$ \\
\hline $\begin{array}{l}\text { Co-morbidities } \\
\text { Chronic pulmonary disease } \\
\text { Cystic fibrosis or bronchiectasis } \\
\text { Moderate-severe liver disease } \\
\text { Moderate-severe renal disease } \\
\text { Diabetes } \\
\text { HIV/AIDS } \\
\text { CR-GN documented prior to admission } \\
\text { Positive colonization } \\
\text { Prior antibiotic exposure }\end{array}$ & $\begin{array}{c}6(54.5) \\
2(18.2) \\
2(18.2) \\
2(18.2) \\
1(9.1) \\
4(36.4) \\
0(0) \\
0(0) \\
11(91.7)\end{array}$ & $\begin{array}{l}2(16.7) \\
1(8.3) \\
2(15.4) \\
1(8.3) \\
1(8.3) \\
1(8.3) \\
5(38.5) \\
1(7.7) \\
7(53.8)\end{array}$ & $\begin{array}{c}0(0) \\
0(0) \\
1(25.0) \\
1(25.0) \\
0(0) \\
0(0) \\
2(50.0) \\
1(25.0) \\
4(100)\end{array}$ & $\begin{array}{c}8(29.6) \\
3(11.1) \\
5(18.5) \\
4(14.8) \\
2(7.4) \\
5(18.5) \\
7(24.1) \\
2(6.9) \\
22(75.9)\end{array}$ \\
\hline $\begin{array}{l}\text { CR-GN infection site } \\
\text { Respiratory tract } \\
\text { Ventilator-associated } \\
\text { Bloodstream } \\
\text { CVC-related } \\
\text { Urinary tract } \\
\text { Catheter-related } \\
\text { Skin and soft tissue } \\
\text { Total length of stay, days, median (range) } \\
\text { Number of patients admitted to ICU } \\
\text { Duration in ICU, days, median (range) } \\
\text { Number of patients requiring isolation } \\
\text { Duration in isolation, days, median (range) } \\
\text { Days from culture to pathogen ID, median (range) } \\
\text { Days from culture to patient isolation, median (range) } \\
\text { Total number of different GN antibiotics prescribed }\end{array}$ & $\begin{array}{c}9(75.0) \\
4(44.4) \\
3(25.0) \\
1(33.3) \\
0(0) \\
0(0) \\
0(0) \\
27.5(9-75) \\
6(50.0) \\
24.0(11-27) \\
12(100.0) \\
10.0(2-75) \\
5(3-9) \\
4.5(-3-9) \\
12\end{array}$ & $\begin{array}{c}8(61.5) \\
6(75.0) \\
0(0) \\
0(0) \\
2(15.4) \\
2(100) \\
2(15.4) \\
36(12-127) \\
6(46.2) \\
32.5(4-42) \\
13(100.0) \\
14.0(5-98) \\
5(4-6) \\
5(-22-14) \\
14\end{array}$ & $\begin{array}{c}2(50.0) \\
1(50.0) \\
1(25.0) \\
0(0) \\
1(25.0) \\
1(100) \\
0(0) \\
17.5(7-85) \\
1(25.0) \\
6.0(6) \\
4(100.0) \\
11.5(7-56) \\
5(4-5) \\
4(1-5) \\
10\end{array}$ & $\begin{array}{c}19(65.5) \\
11(57.8) \\
4(13.8) \\
1(25.0) \\
3(10.3) \\
3(100) \\
2(6.9) \\
28(7-127) \\
13(44.8) \\
24.0(4-42) \\
29(100.0) \\
11.5(2-98) \\
5(3-9) \\
5(-22-14) \\
17\end{array}$ \\
\hline $\begin{array}{l}\text { Patients treated by antibiotic class }{ }^{\mathrm{b}} \\
3^{\text {rd }} / 4^{\text {th }} \text { generation cephalosporin } \\
\text { Beta-lactam/inhibitor combination } \\
\text { Carbapenem } \\
\text { Fluoroquinolone } \\
\text { Aminoglycoside } \\
\text { Macrolide (azithromycin) } \\
\text { Tetracycline (tigecycline) } \\
\text { Polymyxin (colistin) } \\
\text { Patients discharged alive } \\
\text { Patients discharged without antibiotics } \\
\text { Patients discharged with antibiotics } \\
\text { All-cause mortality }\end{array}$ & $\begin{array}{c}2(16.7) \\
9(75.0) \\
11(91.7) \\
3(25.0) \\
1(8.3) \\
1(8.3) \\
0(0) \\
7(58.3) \\
8(66.7) \\
5(41.7) \\
3(25.0) \\
4(33.3)\end{array}$ & $\begin{array}{c}4(33.3) \\
3(25.0) \\
7(58.3) \\
5(41.6) \\
7(58.3) \\
1(8.3) \\
0(0) \\
9(75) \\
9(69.2) \\
6(46.2) \\
3(23.1) \\
4(30.8)\end{array}$ & $\begin{array}{c}1(25.0) \\
1(25.0) \\
3(75.0) \\
1(25.0) \\
4(100) \\
0(0) \\
1(25.0) \\
3(75.0) \\
4(100) \\
0(0) \\
4(100) \\
0(0)\end{array}$ & $\begin{array}{c}7(25.0) \\
13(46.4) \\
21(75.0) \\
9(32.1) \\
12(42.9) \\
2(7.1) \\
1(3.6) \\
19(67.9) \\
21(72.4) \\
11(37.9) \\
10(34.5) \\
8(27.6)\end{array}$ \\
\hline
\end{tabular}

Data are presented as $n(\%)$ unless otherwise indicated. ${ }^{a} \mathrm{n}=27$, patients could have more than one co-morbidity. ${ }^{\mathrm{b}} \mathrm{n}=28$ patients received treatment. SD, standard deviation; MCF, medical care facility; HIV, human immunodeficiency virus; AIDS, acquired immune deficiency syndrome; CR, carbapenem-resistant; GN, Gram-negative; CVC, central venous catheter; ICU, intensive care unit; ID, identification. 
with the majority admitted from medical care facilities $(44.8 \%)$ or the emergency room $(41.4 \%)$; four $(13.8 \%)$ patients were admitted directly (Table 1). At time of admission, presence of a CR-GN pathogen was unknown in $22(75.9 \%)$ patients. Seven patients $(24.1 \%)$ had a pre-existing CR-GN infection, of which four were $P$. aeruginosa respiratory tract infections, with $1 / 4$ positive for respiratory colonization. Most patients $(55.2 \%)$ reported underlying respiratory infections, of whom $31.3 \%$ had a known background of tuberculosis. Other co-morbidities included $29.6 \%$ chronic pulmonary disease, $18.5 \%$ liver disease, $18.5 \%$ HIV/AIDS, and $14.8 \%$ renal disease.

The respiratory tract was the most common site of infection (19/29 patients, $65.5 \%$ ); and $11 / 19$ cases required ventilation. Of these 19 patients, nine (47.4\%) were infected with $A$. baumannii, eight $(42.1 \%)$ with $P$. aeruginosa, and two $(10.5 \%)$ with $K$. pneumoniae. Other sites of infection included bloodstream (13.8\%), urinary tract $(10.3 \%)$, and skin and soft tissue $(6.9 \%)$.

Duration of hospitalization ranged from 7-127 days (median 28.0 days) and was independent of the type of pathogen diagnosed. Overall, $44.8 \%$ of patients were admitted to the intensive care unit (ICU) during hospitalization (84.6\% within $24 \mathrm{~h}$ ), mainly related to respiratory failure or septic shock (69.2\%). Length of ICU stay varied (4-42 days), with $76.9 \%$ of patients remaining for $>2$ weeks, and $30.8 \%$ remaining for $>4$ weeks. Median duration of ICU stay for patients infected with $P$. aeruginosa or $A$. baumannii (each $\mathrm{n}=6$ ) was 32.5 days and 24.0 days, respectively; $66.7 \%$ of $P$. aeruginosa infections required an ICU stay $>30$ days. Only one of four patients infected with $K$. pneumonia required an ICU stay, which was 6.0 days. The time taken from sending a respiratory sample for culture to receipt of results ranged from 3-9 days; $31.6 \%$ of results were reported within 4 days, with $89.5 \%$ by Day 5 . All patients were either isolated or placed in single occupancy rooms with standard infection prevention and control precautions upon CR-GN infection diagnosis. Duration of isolation was similar for all three pathogens (10-14 days). However, for $>50 \%$ of patients there was a delay of $\geq 5$ days before isolation, representing a potential risk for spread of resistance and outbreaks.

Automated antimicrobial susceptibility testing was performed on all isolates; however, rapid diagnostic tests (polymerase chain reaction or phenotypic assays) were not routinely used to confirm carbapenem resistance. In the 19 patients with respiratory CR-GN infections, carbapenem resis- tance was most frequently observed in nonfermentative bacteria with $A$. baumannii and $P$. aeruginosa representing $47.4 \%$ and $42.1 \%$ respectively, compared with $10.5 \%$ K. pneumoniae. This ratio was in line with the overall patient population $(n=29)$, with $86.2 \%$ of infections associated with nonfermenters. Eight $P$. aeruginosa isolates were resistant to imipenem or meropenem, of which five $(62.5 \%)$ were resistant to both. Detailed characterization of carbapenem resistance was only performed for meropenem-resistant $K$. pneumoniae isolates, all of which carried the KPC carbapenemase gene.

In total, 15/19 (78.9\%) patients with respiratory infections had received $\geq 1$ antibiotic before a specimen was taken for culture, consistent with the overall population (22 of 29 patients, $75.9 \%$ ); for $21 / 29$ $(72.4 \%)$ patients this included a carbapenem. Treatment was empiric for $47.6 \%$ of patients, with the remainder being given to treat existing concomitant infections. The antibiotics chosen to treat CR-GN infection were heterogeneous, reflecting the complex patient cohort, with a total of 17 different antibiotics with GN activity being prescribed (excluding those prescribed for concurrent Gram-positive or tuberculosis infections). Among the 19 patients with respiratory infections, $13(68.4 \%)$ received treatment with colistin, and $14(73.7 \%)$ received a carbapenem during their period of hospitalization, reflecting the limited therapeutic options for CR-GN infections.

Overall, 21/29 (72.4\%) patients, and $13 / 19(68.4 \%)$ patients with respiratory infections were discharged alive; 11/29 (37.9\%) patients were discharged without any further antibiotics, including all patients with KPC-producing K. pneumoniae. Allcause mortality during hospitalization was $27.6 \%$. No deaths cited CR-GN infection as the primary cause of death; however, it was judged a contributory factor in $87.5 \%$ of cases.

\section{Discussion and Conclusions}

Our survey provides insights into the clinical complexity of managing CR-GN infections in a setting of endemic multidrug resistance, particularly for respiratory infections, which made up the majority of infections in this survey. We show that patients with CR-GN infections may have complex co-morbidities, a long history of prior antibiotic treatment, and referrals across multiple health care facilities. We also identified that most patients admitted to the ICU remained there for $>2$ weeks, demonstrating the difficulties faced around achieving effective management.

A visit to Italy by the European Centre for Disease Control in 2017 concluded that antimicrobial resistance, including carbapenem resistance, poses a major public health threat to the region, and risks compromising key medical services. ${ }^{9}$ Furthermore, a survey of 800 hospitals in Europe and USA reported double combination therapy was almost universally used, with meropenem routinely combined with colistin, despite a lack of robust clinical evidence to support this approach, ${ }^{10}$ reflecting the lack of certainty around effective therapies for CR-GN infections. Early prescription of an effective antibiotic regimen is crucial for the management of severe CRGN infections.

This pilot study was a retrospective, single-center study with a small sample size. Data for the 29 included patients were analyzed based on the baseline pathogen (3 subgroups) or site of infection (4 subgroups), limiting the ability to draw conclusions in each subgroup. However, this study does show the feasibility of this type of chart review. Larger case reviews are warranted for optimizing management of CRGN infections.

\section{References}

1. Center for Disease Control and Prevention. Antibiotic Resistance Threats in the US, Biggest Threats and Data. Washington: Center for Disease Control and Prevention; 2013. Available from: https://www.cdc.gov /drugresistance/threat-report2013/index.html

2. European Centre for Disease Prevention and Control. Plasmid-mediated colistin resistance in Enterobacteriaceae, 15 June 2016. Stockholm: ECDC; 2016. Available

from: https://www.ecdc.europa.eu/en/publications-data/rapid-risk-assessment-plasmid-mediated-colistin-resistance-enterobacteriaceae- 15

3. World Health Organization. Prioritization of pathogens to guide discovery, research and development of new antibiotics for drug-resistant bacterial infections, including tuberculosis. Geneva: World Health Organization; 2017. (WHO/EMP/IAU/2017.12) Available from: https://www.who.int/medicines/areas/ra tional_use/PPLreport_2017_09_19.pdf ?ua $=1$

4. European Centre for Disease Prevention and Control. Antimicrobial resistance surveillance in Europe 2016. Annual 
Report of the European Antimicrobial Resistance Surveillance Network (EARS-Net). Stockholm: ECDC; 2017. Available from: https://www.ecdc. europa.eu/sites/default/files/documents/AMR-surveillance-Europe2016.pdf

5. Simoni S, Morroni G, Brenciani A, et al. Spread of colistin resistance gene mcr-1 in Italy: characterization of the mcr-1.2 allelic variant in a colistinresistant blood isolate of Escherichia coli. Diag Micro Infect Dis 2018;91:668

6. Zilberberg MD, Shorr AF, Micek ST. Multi-drug resistance, inappropriate initial antibiotic therapy and mortality in
Gram-negative severe sepsis and septic shock: a retrospective cohort study. Crit Care 2014;18:596

7. Cassini A, Högberg LD, Plachouras D, et al. Attributable deaths and disabilityadjusted life-years caused by infections with antibiotic-resistant bacteria in the EU and the European Economic Area in 2015: a population-level modelling analysis. Lancet Infect Dis 2019;19:5666

8. Britt NS, Ritchie DJ, Kollef MH, et al. Importance of Site of Infection and Antibiotic Selection in the Treatment of Carbapenem-Resistant Pseudomonas aeruginosa Sepsis. Antimicrob Agents Chemother 2017;62:e2400 17
9. European Centre for Disease Prevention and Control. ECDC country visit to Italy to discuss antimicrobial resistance issues. Stockholm: ECDC; 2017. Available from: https://www.ecdc.europa.eu/en/publications-data/ecdc-country-visit-italy-discuss-antimicrobial-resistance-issues

10. Papst L, Beović B, Pulcini C, et al. Antibiotic treatment of infections caused by carbapenem-resistant Gram negative bacilli: an international ESCMID cross-sectional survey among infection diseases specialists practicing in large hospitals. Clin Micro Infect 2018;24:1070-6. 